\title{
$+2$ \\ Drugs prescription in patients with chronic liver disease: rules for adjusting doses and beyond
}

The liver is the primary organ where biotransformation processes for drugs and other xenobiotics, necessary to turn originally fat-soluble compounds into more polar substances to facilitate urinary clearance, take place. Therefore, liver disease commonly brings about changes in the metabolism of multiple drugs. In addition to pharmacokinetic changes, chronic liver disease (particularly decompensated liver cirrhosis) induces changes (that is, an abnormal response) in the pharmacodynamics of various drugs and increases the severity of potential adverse events.

While the spectrum of liver disease is wide, and hepatic functioning is preserved in many liver conditions, liver disorders are usually associated with physiological and/or structural changes that decrease the liver's metabolic capacity. Firstly, the absorption of a number of drugs may be disrupted by intestinal permeability changes that are characteristic of portal hypertension as well as by altered gastric voiding and bowel motility. Also, necrosis and liver cell dysfunction reduce the levels of liver enzymes responsible for drug metabolism, which affects plasma levels of active principles and hence their effectiveness and potential toxicity. On the other hand, altered liver structure and both intra- and extra-hepatic portosystemic shunts impair presystemic drug clearance for compounds with a high hepatic extraction ratio. Similarly, the synthesis of plasma transport proteins, basically albumin and alfa-glycoprotein, may be reduced, which affects the bioavailability of drugs highly bound to plasma proteins; drug excretion may become disrupted by variable cholestasis and, on occasion, renal impairment. Finally, advanced liver cirrhosis develops with an abnormal (usually exaggerated, deleterious) response to a number of drugs, including benzodiazepines, opiates, and non-steroidal antiinflammatory drugs (1). No wonder then that no single biochemical parameter (albumin, prothrombin activity) or cluster thereof is predictive of drug metabolism. Only general recommendations are issued that rely on a classification of drugs according to their flow-dependent, first-pass extraction ratio, their liver metabolism extent, and -within the latter group- their plasma protein binding degree (2); however, such proposal is a theoretical approach that more often than not is neither based on kinetic studies nor validated in prospective trials. In the present issue of The Spanish Journal of Gastroenterology, Periáñez et al. (3) make an attempt at issuing recommendations for the proper use of drugs in patients with chronic liver disease by using a strategy based on thoroughly reviewing prescribing information sheets, pharmaceutical databases, review articles, and the WHO list of drugs to be excluded or used cautiously in patients with liver disease, adding novel therapies, and adjusting said assessment to hospital medication guidelines. For cases where no relevant information could be found, adjustment recommendations followed the procedure defined by Delcò et al. (2). This strategy provides a list of recommendations that may be useful to clinicians in the hospital setting who must prescribe medications for 
patients with cirrhosis, most particularly since it provides a rapid search and summarizes items to be considered for proper dosing as well as options to be avoided. However, many gaps remain inevitable as neither during drug development nor post-marketing studies are available that have examined the kinetics and response, as well as the potential toxicities of most drugs in this population. Although both the FDA and EMA demand since 2003 and 2005, respectively, that kinetic studies be performed before registration in patients with cirrhosis should the drug undergo significant hepatic metabolism, these studies are carried out in patients with preserved liver function (Child-Pugh A) and results can hardly be extrapolated to drugs with linear dynamics for dose titration purposes, since differences in liver metabolism are sometimes only apparent in Child-Pugh C patients (4).

In association with the update suggested by studies such as the one by Periáñez et al. (3), knowing the attitudes of clinicians when prescribing drugs for patients with liver disease would be useful to identify behaviors susceptible of intervention should deviation from scientific evidence occur. However, very few such surveys have been reported. A survey in four US healthcare areas among internists, general practitioners and specialists revealed a lower trend towards discouraging the use of NSAIDs versus paracetamol in patients with both compensated and decompensated cirrhosis; however, while non-specialists were less apt to recommend paracetamol versus NSAIDs for these patients, specialists had the opposite behavior. Anyway, the caution usually displayed by respondents suggests that pain management in cirrhosis might be insufficiently approached (5). On the other hand, a survey carried out in Spain a few years ago to review the way gastroenterology/hepatology specialists use drugs in inpatients with liver cirrhosis similarly showed a conservative attitude with a tendency to prescribe an average $<1$ of the daily dose defined for drugs most commonly indicated for conditions associated with liver disease (including paracetamol, glibenclamide, lorazepam, captopril, and tiapride), with clomethiazole and amoxicillin-clavulanic -the use of which is controversial in the setting of cirrhosis- at the top of the list (6). However, the most relevant finding by this extensive survey was a high variability in prescription patterns for drugs indicated in liver conditions, with a relevant use of drugs such as vitamin $\mathrm{K}$ and proton-pump inhibitors (PPIs) (7). This finding was hardly surprising regarding PPIs, given the widespread tendency of physicians to prescribe them as "protectors" particularly in frail subjects such as elderly, polymedicated individuals, or patients with chronic conditions such as cirrhosis. In the latter case a study to assess PPI indication in this population found that 51/128 patients (40\%) received antisecretory drugs, the indication (history of portal hypertension-related bleeding) being unwarranted in $63 \%$ (8). In fact, in the context of cirrhosis PPIs are indicated primarily for patients with esophageal varices or gastric disease related to portal hypertension, particularly those undergoing endoscopic therapy. Nevertheless, a number of studies have shown these agents to be ineffective both in the prevention and management of portal hypertension-related bleeding $(9,10)$, and in the prevention and management of ulcers following sclerotherapy or band ligation (11). While this antisecretory prescribing behavior for cirrhotic patients merely was a non-evidence-based -and therefore non-cost-effective- deviation (12), recent studies clearly show that PPI use is not without risks. These drugs increase fracture risk in frail subjects (13), and various studies suggest that PPIinduced antisecretion favors bacterial overgrowth and bacterial translocation in the setting of increased bowel permeability as seen in portal hypertension (14), thus increasing the risk for spontaneous bacterial peritonitis (15). While the studies that revealed an association with bacterial peritonitis are retrospective and some of them had small cohorts and inconsistent results, a recent meta-analysis including almost 800 patients 
confirmed such association and showed that PPIs induce a 3-fold increase in this cirrhotic complication $(\mathrm{OR}=2.77 ; 95 \% \mathrm{CI}$ : 1.82-4.23) (16). The risk for infection in cirrhotic patients exposed to PPIs is not restricted to spontaneous bacterial peritonitis but is also linked to Clostridium difficile infection (17), a condition with a high death rate in patients with liver cirrhosis. In fact, prior PPI use was the weightiest risk factor in the multivariate analysis $-\mathrm{OR}=37.6$ (95\% CI: 6.22-227.6), $\mathrm{p}<0.0005-$, even above inpatient antibiotic use -OR $=11.6$ (95\% CI: 2.63-51.05), $\mathrm{p}<0.001-$. While this association is no evidence for causality -particularly given that Clostridium difficile spores are acid-resistant, and the potential impact of avoiding antisecretory drugs on this infection remains unknown (18), it does represent, together with the above evidence, a warning to physicians, particularly those involved in caring for patients with liver disease, regarding the fact that efforts should be devoted to reviewing every patient on these drugs in order to withdraw such medication if no indication is warranted. Further studies are thus needed to assess the prescription-related beliefs and attitudes of gastroenterologists regarding these medications in cirrhotic patients. This group represents the primary target for any field studies and resulting interventions, not only because they hold the maximum responsibility in decision-making regarding the medication of patients with chronic liver disease, but also because of the multiplying effect any educational program targeting them will have on other groups such as the internists and general practitioners involved in the management of these patients.

\section{Raúl J. Andrade ${ }^{1}$ and M. Isabel Lucena ${ }^{2}$}

${ }^{1}$ Unit of Digestive Gestion Clinic. ${ }^{2}$ Department of Farmacology Clinic. University Hospital Virgen de la Victoria. School of Medicine. Málaga, Spain.

Centro de Investigación Biomédica en Red de Enfermedades Hepáticas y Digestivas (CIBERehd). Barcelona, Spain

\section{REFERENCES}

1. Andrade RJ, Lucena MI. ¿Cómo usar correctamente los fármacos en pacientes con enfermedades hepáticas? Gastroenterol Hepatol 2012;35:28-37.

2. Delcò F, Tchambaz L, Schlienger R, Drewe J, Krahenbuhl S. Dose adjustment in patients with liver disease. Drug Saf 2005;28:529-45.

3. Periáñez-Párraga L, Martínez-López I, Ventayol-Bosch P, Puigventós-Latorre F, Delgado-Sánchez O. Drug dosage recommendations in patients with chronic liver disease. Rev Esp Enf Dig 2012;104(4):165-84.

4. Brockmöller J, Thomsen T, Wittstock M, Coupez R, Lochs H, Roots I. Pharmacokinetics of levetiracetam in patients with moderate to severe liver cirrhosis (Child-Pugh classes A, B, and C): characterization by dynamic liver function tests. Clin Pharmacol Ther 2005;77:529-41.

5. Rossi S, Assis DN, Awsare M, Brunner M, Skole K, Rai J, et al. Use of over-the-counter analgesics in patients with chronic liver disease: physicians' recommendations. Drug Saf 2008;31:261-70.

6. Lucena MI, Andrade RJ, Tognoni G, Hidalgo R, Sánchez de la Cuesta F. Drug use for non-hepatic associated conditions in patients with liver cirrhosis. Eur J Clin Pharmacol 2003;59:71-6.

7. Lucena MI, Andrade RJ, Tognoni G, Hidalgo R, Sánchez de la Cuesta F. Multicenter hospital study on prescribing patterns for prophylaxis and treatment of complications of cirrhosis. Eur J Clin Pharmacol 2002;58:435-40.

8. Kalaitzakis E, Björnsson E. Inadequate use of proton-pump inhibitors in patients with liver cirrhosis. Eur J Gastroenterol Hepatol 2008;20:512-8.

9. Alaniz C, Mohammad RA, Welage LS. Continouos infusion of pantoprazole with octreotide does not improve management of variceal hemorrhage. Pharmacotherapy 2009:29:248-54.

10. García-Sáenz de Sicilia M, Sánchez-Ávila F, Chávez-Tapia NC, López-Arce G, García-Osogobio S, RuizCordero R, et al. PPIs are not associated with a lower incidence of portal hypertensive- related bleeding in cirrhosis. World J Gastroenterol 2010;16:5869-73.

11. Garg PK, Sidhu SS, Bhargave DK. Role of omeprazole in prevention and treatment of of postendoscopic variceal sclerotherapy esophageal complications. Dig Dis Sci 1995;40:1569-74.

12. Lodato F, Azzaroli F, Di Girolamo M, Feletti V, Cecinato P, Lisotti A, et al. Proton pump inhibitors in cirrhosis: Tradition or evidence based practice? World J Gastroenterol 2008;14:2980-5. 
13. Corley DA, Kubo A, Zhao W, Quesenberry C. Proton-pump inhibitors and histamine-2 receptor antagonists are associated with hip fractures among at-risk patients. Gastroenterology 2010;193:93-101.

14. Van Vlerken LG, Huisman EJ, van Hoeck B, Renooij W, de Rooij FWM, Sieserma PD. Bacterial infections in cirrhosis: role of proton pump inhibitors. Eur J Clin Invest 2011; Dec 30. doi: 10.1111/j.13652362.2011.02643.x. [Epub ahead of print]

15. Bajaj JS, Zadvornova Y, Heuman DM, Hafeezullah M, Hoffmann, RG, Sanyal AJ, et al. Association of proton pump inhibitor therapy with spontaneous bacterial peritonitis in cirrhotic patients with ascites. Am J Gastroenterol 2009;104:1130-4

16. Trikunadathan G, Israel J, Cappa J, O’Sullivan DM. Association between proton pump inhibitors and spontaneous bacterial peritonitis in cirrhotic patients - a systematic review and meta-analysis. Int J Clin Pract 2011;65:674-8.

17. Bajaj JS, Ananthakrishnan AN, Hafeezullah M, Zadvornova Y, Day A, McGinley EL, et al. Clostridium difficile is associated with poor outcomes in patients with cirrhosis: a national and tertiary center perspective. Am J Gastroenterol 2010;105:106-13.

18. Garcia-Tsao G, Surawicz C. Clostridium difficile infection: yet another predictor of poor outcome in cirrhosis Am J Gastroenterol 2010;114-6. 